\title{
The behaviour of Akashi Kaikyo Bridge under multi support seismic excitation for low frequency motions
}

\author{
L. Bahbouh, H. Yamada, H. Katsuchi, E. Sasaki \& C. Theeraphong \\ Department of Civil Engineering, Yokohama National University, Japan
}

\begin{abstract}
The purpose of this study is to investigate the behaviour of Akashi Kaikyo Bridge under low frequency multi support seismic excitations which will amplify the bridge response owing to the resonance phenomena impact. Nonlinear static and modal dynamic analyses for seismic waves of different propagation velocities are conducted. It is observed that the propagation wave velocities have a significant effect on the bridge, and the bridge response to different asynchronous input motions at the towers and abutments bases consists of the dynamic component induced by the inertia forces, and the pseudo static component results from the difference between the adjacent supports displacements. For low travelling wave velocities, the response which varies with the velocity is increased due to the pseudo static component. But as the travelling wave velocity grows, the dynamic component increase to be preeminent for infinite propagation velocities. These results are pronounced largely when the travelling seismic waves have dominant low frequencies might coincide some of the bridge frequencies even for high vibrating modes. Therefore, it is required to investigate the response of long span suspension bridges under low frequency travelling seismic excitations.
\end{abstract}

Keywords: Akashi Kaikyo Bridge, low frequency multi support excitation.

\section{Introduction}

Long span structures such as suspension and cable stayed bridges can be subjected to different ground motions along their length due to the spatial variability of the seismic excitation. The spatial variation of seismic motion has been of concern for a number of decades, and it was considered as the result of 
three phenomena: the wave passage effect due the difference in the waves arrival times at the supports, the incoherency effect resulting from the waves refraction and retractions during their propagation, and the local site effect due to the difference in local soil conditions at each location.

Wang et al. [1] found that the incoherency of the seismic waves is less important than the travelling effect and the errors of ignoring this factor are less than $15 \%$ in the relative displacement estimation. The influence of wave passage effect on the responses of bridges has been investigated by several researchers, for instance [2-7]. Tzanetos et al. [8] and Wang et al. [9] have studied the wave passage effect on the inelastic responses of symmetric and asymmetric bridge structures, they concluded that special consideration should be given to bridges under travelling ground motions since they may respond in higher modes and the demands are likely to increase on the bridges. However, most of these studies focus mainly on the bridge elastic and nonlinear behaviour under general travelling seismic excitation, paying almost no attention to the characteristics of the propagated seismic waves such as dominant frequency ranges, duration, and the released energy. From the other hand and based on the observed structural damage patterns from some previous earthquakes and according to some recent analytical studies [10-13], low frequency input ground motion has been identified as a major source of unfavourable enlarged response of medium and long span structures, where the resonance phenomena due to the matching between the structure and earthquake dominant frequencies is prominent.

In this paper, a study of Akashi Kaikyo Bridge under low frequency travelling seismic excitation was carried out in the transverse and longitudinal directions. It is assumed that the spatial variability is attributed only to the wave passage effect where the incoherency effect was ignored. Parametric analysis using different propagation velocities of the seismic waves and different time histories of low and high frequencies were conducted to assess both, the low frequency effect and the wave passage effect on the bridge response. The response of the bridge to asynchronous input motions at different supports consists of two components, a dynamic component induced by inertia forces, and a pseudo static component due to the difference between the adjacent support displacements, Clough and Penzien [14]. It is observed that the propagation velocity of seismic waves has a significant effect on the bridge response, especially under low frequency earthquake input. For low travelling velocities, the pseudo static component contribution to the response is significant, and then it is reduced considerably for large velocities where the response is dominated by the dynamic component.

\section{Low frequency seismic excitation}

Low frequency seismic excitations are low frequency ground motions of dominant frequency band about $1-3 \mathrm{~Hz}$. These motions are generated by the slow shear slip in the plate interface during the seismic transient events. Or due to the temporary source effects which will delay slow down and decrease the fluctuation's amplitude, Ide and Shelly [15]. Thus, these oscillations do not necessary have large acceleration amplitude. On the other hand, some of these 
events could fairly have large velocity amplitude and localized peak within the displacement response spectrum, Jousset and Douglas [16]. Low frequency waves are more efficient than high frequency waves causing large vibrations in long span structures. Since the amplitude range of low frequency vibrations decays less rapidly than high frequency vibrations as the distance from the fault increases, long structures which locate at relatively great distances from the fault are exposed to damage due to the large induced vibrations, Hays [17]. Low frequency ground motions are sensitive to the site and propagation velocity effects, thus their impact on long span structures should be studied under different travelling wave velocities.

\section{Objectives of study}

There are three objectives of this study:

1. Model Akashi Kaikyo Bridge and verify its natural frequencies and mode shapes.

2. Investigate the bridge dynamic and pseudo static responses under different asynchronous motions, and observe the larger response which corresponds to the low frequency earthquake impact.

3. Analyse the responses at some nodes of the bridge model under different travelling wave velocities. For instance, N436 responses are shown in this paper.

\section{Akashi Kaikyo Bridge model and modal analysis}

Akashi Kaikyo Bridge is a two-hinged three spans stiffening truss suspension bridge with a total length $3910 \mathrm{~m}$, fig. 1 .

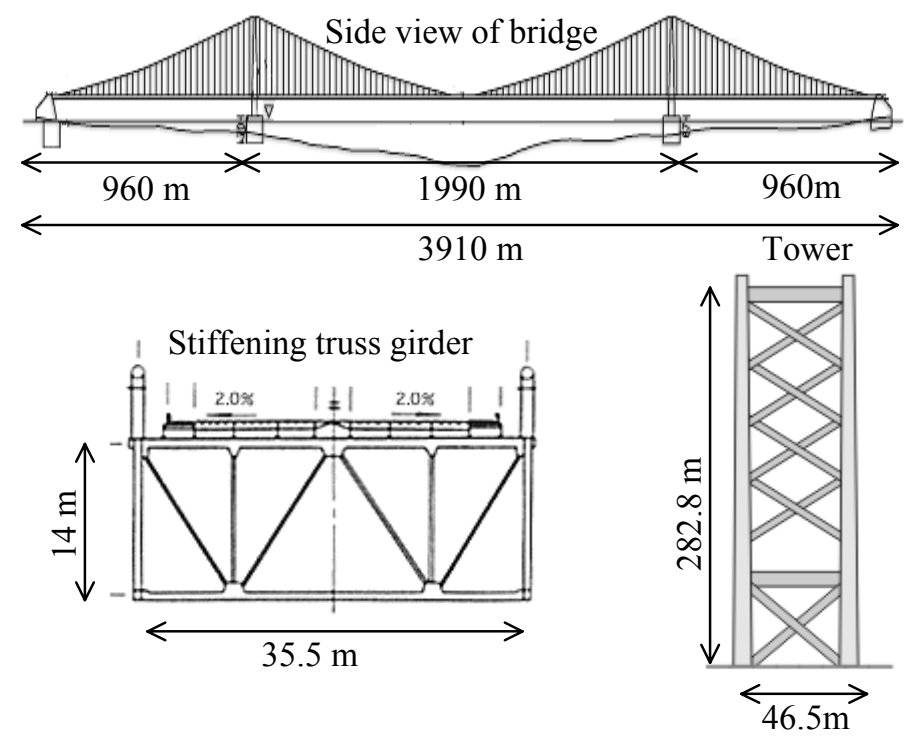

Figure 1: General plan of Akashi Kaikyo Bridge. 
As fig. 2 shows, the bridge is modelled using the fish bone finite element model, in which the stiffening girder is replaced with a spine of beam elements which pass the shear centre of the stiffening girder. Specified lumped masses of spatial masses and mass moment of inertia about the spine longitudinal direction are distributed. Another beam elements and lumped masses are used to model the tower. Hypothetical over hanging rigid members are set between the hanger fixtures and the spine. The girder end is connected to the tower by a link bearing of beam elements with larger rigidity than that of the hanger rope, and the stress from vertical shear force is dominant.

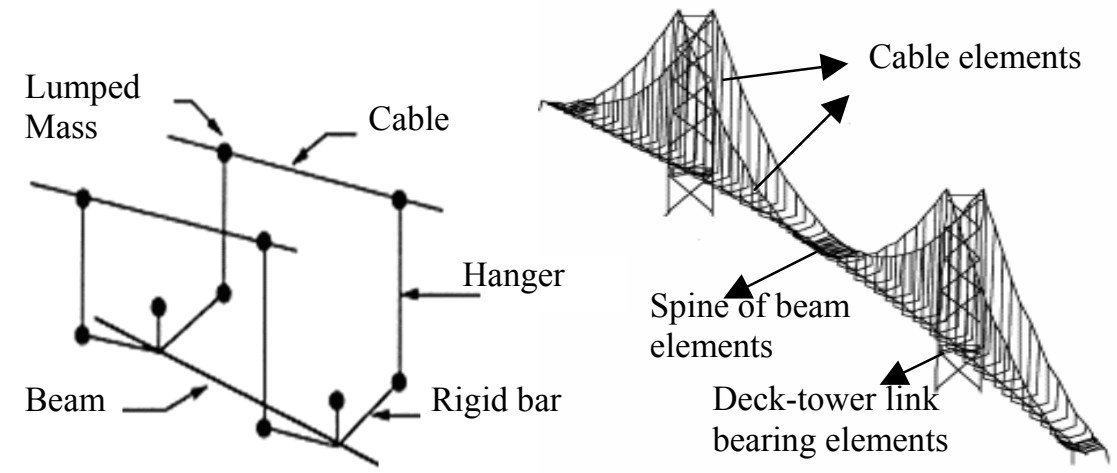

Figure 2: $\quad$ Akashi Kaikyo Bridge model.
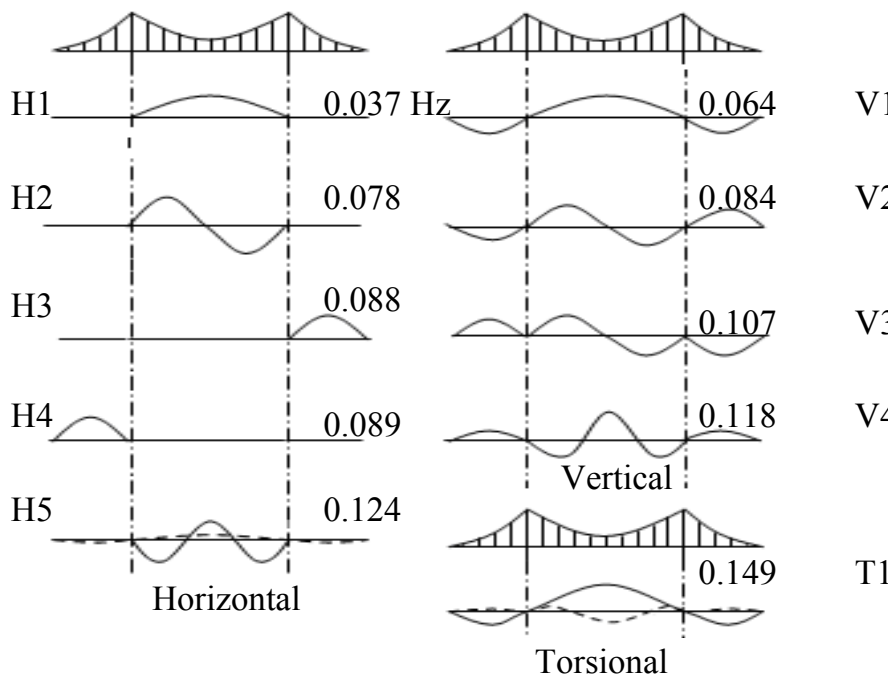

Figure 3: First ten dominant mode shapes of the bridge. 
Static nonlinear analyses which incorporate geometric nonlinearity, large displacements, p-delta effect and sag effect in the cables were conducted. And then modal analyses which incorporate the first sixty fundamental modes of the bridge model were concluded. Fig. 3 shows the first ten mode shapes and natural frequencies of the bridge. The calculated natural frequencies and mode shapes collaborate well with the obtained one according to Honhu-Shikoku Bridge Authority record.

\section{Earthquake records and arias intensity}

For engineering applications, several parameters proposed as a measure of ground shaking, including mainly peak ground acceleration, power spectral density, earthquake duration and Arias intensity (energy), Hwang et al. [18], fig 4 .
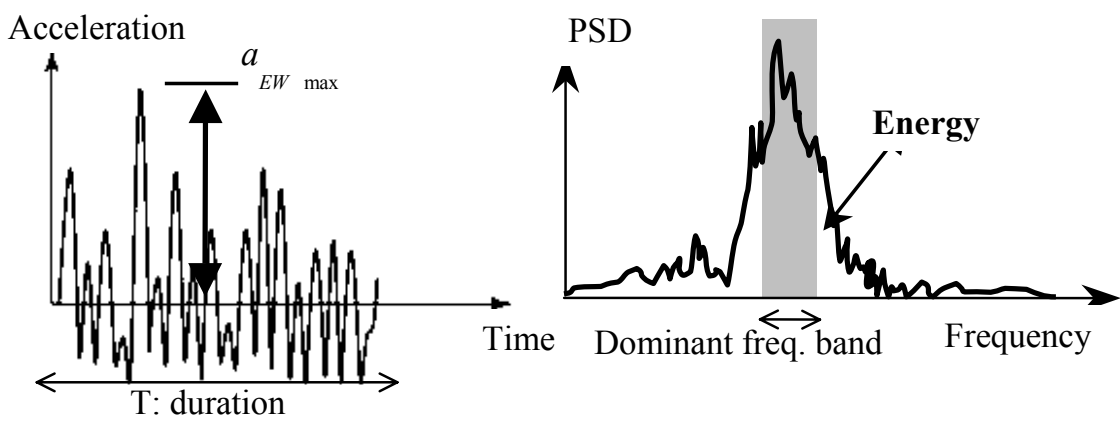

Figure 4: $\quad$ Frequency domain and energy component.

In this study, we focus on the dominant frequency impact of low frequency earthquakes on the bridge, thus we need to reduce the influence of the other parameters which characterize the earthquake. Arias intensity is an attractive earthquake measure since it takes into account the amplitude and the total duration of earthquake. Therefore, a comparative analysis between the impact of different earthquakes of similar released energy component but different dominant frequencies sounds to be reasonable for this study. Arias intensity is derived from the integration of the square of the entire acceleration record, and for ground acceleration in the east west direction it is determined as eqn. (1):

$$
I_{E W}=\frac{\pi}{2 g} \int_{0}^{t_{0}}\left[a_{E W}(t)\right]^{2} d t
$$

The total Arias intensity is defined as the sum of the two horizontal Arias intensities in east west-direction and north-south direction

From the United States USGS earthquake hazards program, five ground motions with high and low dominant frequencies were selected and their Arias intensities in both horizontal directions were unified to match the intensity 
generated by one of them. The Arias intensity and the dominant frequencies are shown in table 1.

Table 1: $\quad$ Earthquake records and dominant frequencies.

\begin{tabular}{|c|c|c|c|c|c|c|}
\hline \multicolumn{2}{|c|}{ Record } & $\begin{array}{c}\mathrm{T} \\
(\mathrm{sec})\end{array}$ & $\begin{array}{c}\text { Acc } \\
(\mathrm{m} / \mathrm{sec} 2)\end{array}$ & $\sum[a(t)]^{2}$ & $\begin{array}{c}E=\frac{\pi}{2 g} \sum[a(t)]^{2} \\
(\mathrm{~m} / \mathrm{sec})\end{array}$ & $\begin{array}{c}\text { Dominant } \\
\text { Freq. } \\
(\mathrm{Hz})\end{array}$ \\
\hline \multirow{2}{*}{ Petrolia } & EW & \multirow{2}{*}{60} & -7.428 & \multirow{10}{*}{$\begin{array}{c}(\mathrm{EW}) \\
1770.7148 \\
(\mathrm{NS}) \\
1361.4900\end{array}$} & \multirow{10}{*}{$\begin{array}{l}283.3866 \\
217.8939\end{array}$} & 1.350 \\
\hline & $\mathrm{NS}$ & & +6.93 & & & 1.188 \\
\hline \multirow{2}{*}{ Sylmarff } & EW & \multirow{2}{*}{60} & +8.796 & & & 0.651 \\
\hline & $\mathrm{NS}$ & & +7.665 & & & 1.578 \\
\hline \multirow{2}{*}{ Newhall } & EW & \multirow{2}{*}{60} & +5.782 & & & 1.432 \\
\hline & $\mathrm{NS}$ & & -5.716 & & & 1.725 \\
\hline \multirow{2}{*}{ Smonica } & EW & \multirow{2}{*}{60} & -7.944 & & & 2.685 \\
\hline & NS & & -10.70 & & & 4.394 \\
\hline \multirow{2}{*}{ Lucerne } & EW & \multirow{2}{*}{48} & -6.184 & & & 11.458 \\
\hline & $\mathrm{NS}$ & & -5.536 & & & 11.42 \\
\hline
\end{tabular}

\section{Earthquake response of the bridge}

The mentioned earthquake records were applied with EW component in the transverse direction and NS component in the longitudinal direction of deck. And the deck and towers responses were obtained under asynchronous motions then compared to the response under synchronous motion, where the term "synchronous" refers to the case when all supports (towers and abutments) undergo the same simultaneous motion, whereas the term "asynchronous" refers to the travelling wave situation with time lags between supports. The investigated parameters are the maximum drifts of deck and towers in the longitudinal direction under $300 \mathrm{~m} / \mathrm{sec}$ propagation wave velocity, fig. 5 and fig. 6 .

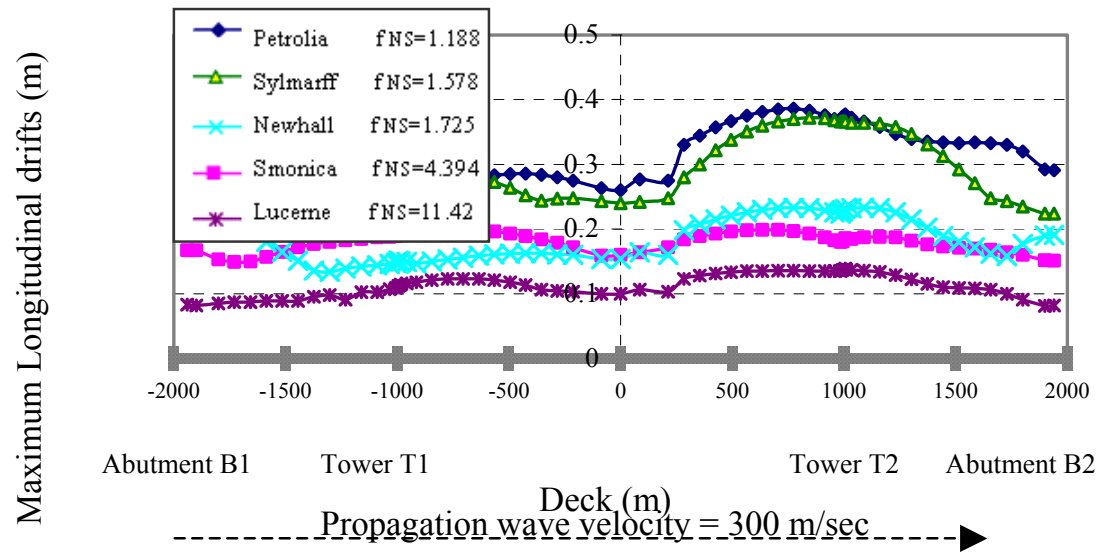

Figure 5: Maximum drifts of the deck in longitudinal direction under different earthquakes with different frequencies (Asynchronous motions). 
Figs.5,6 show that the maximum drifts along the deck and towers correspond to Petrolia earthquake which has the lowest dominant frequency $(1.18 \mathrm{~Hz})$, followed by Sylmarff earthquake record $(1.578 \mathrm{~Hz})$. On the other hand, the lowest drifts were noticed under Lucerene earthquake which has high dominant frequency $(11.42 \mathrm{~Hz})$ even though all earthquakes have similar arias intensity components. It can be concluded that low frequency earthquakes induce larger response in long span bridges, this is due to the resonance phenomenon which occurs when the frequency of oscillations correspond to (or near) one of the natural frequencies of the bridge which are basically low in long structures. It is noticed also that the multi support excitation effect is much remarkable under low frequency earthquakes (Petrolia and Sylmarff), where the deck response under travelling waves is not symmetric any more and the larger drifts occur close to tower T2. Besides, the response of towers is not identical and the Tower T2 response is larger. This also can be explained by the contribution of higher modes to the response in which the propagated wave that reached the second tower T2 have different low frequencies than the one at the first tower, and these frequencies may match different stronger vibrating frequencies of the bridge.

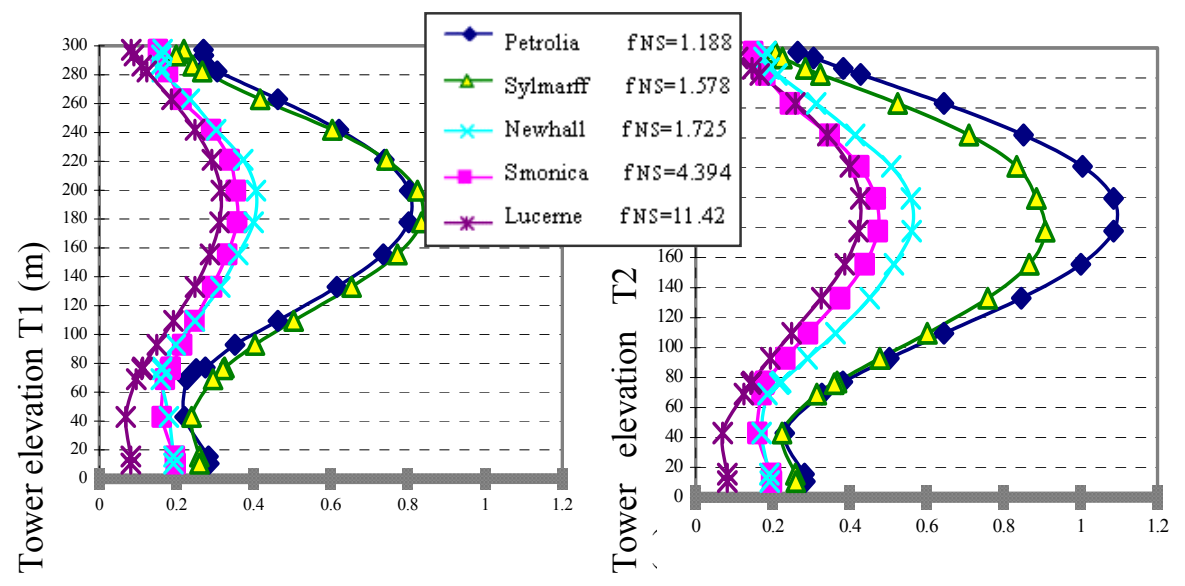

Maximum longitudinal drifts (m)

Figure 6: Maximum drifts of the towers in longitudinal direction under different earthquakes with different frequencies (Asynchronous motions).

The response of the bridge to asynchronous input motions at different supports consists of two components, the dynamic component and the pseudo static component. In order to investigate the vibration of the dynamic component, several synchronous analyses were carried out, and the time histories used in these synchronous cases were considered to present the dynamic response of the asynchronous cases.

Fig. 7 shows the response of the bridge under synchronous and asynchronous motions, the pseudo static component increases the total response mainly, but for 
low frequency earthquakes it reduces the total response of the deck close to the earthquake propagation source (epicentre). Since the pseudo static response cause stresses dependant on the stiffness of the structure, the drifts close to the fixed ends of the girder where the structural stiffness is very large are dominated by the pseudo static component.

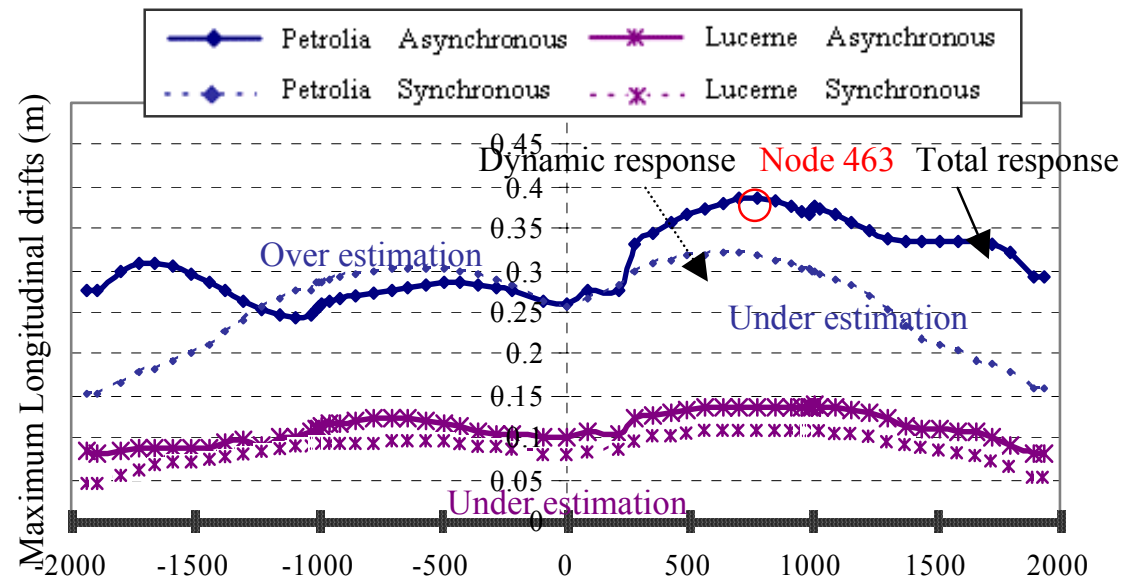

Abutment B1 Tower T1

$\operatorname{Deck}(\mathrm{m})$

Tower T2 Abutment B2

Propagation wave velocity $=300 \mathrm{~m} / \mathrm{sec}$

Figure 7: Maximum drifts under synchronous and asynchronous low and high frequency motions.

As for the deck, the maximum response under travelling velocity $300 \mathrm{~m} / \mathrm{sec}$ was investigated in the Node 436. Its response under other different velocities is described in fig.8. It can be seen that when the time histories travel with velocities higher than $(3000 \mathrm{~m} / \mathrm{sec})$ the maximum drifts are almost the same as the synchronous cases. As for the response under the low frequency earthquake Petrolia and for travelling velocities $(300,500,1000 \mathrm{~m} / \mathrm{sec})$, the pseudo static component increase the response to $18 \%, 66 \%$ and $51 \%$ respectively, then its effect reduce gradually when velocity exceeds $1000 \mathrm{~m} / \mathrm{sec}$. from other hand the drifts increase vary with the low velocities in soft soil $(100-250 \mathrm{~m} / \mathrm{sec})$.

The total response of the bridge structure to asynchronous motion also could be affected by the fact that the frequency spectrum of the excitation to which the whole bridge was subjected was different than that of the synchronous case. The frequency spectrum of the excitation changed with the travelling wave velocity although the time histories of the seismic motion didn't change in shape at the various supports on the ground surface. For simplification, this could be seen for example in fig.9 in the acceleration response spectra of node 436 under Petrolia synchronous and asynchronous $(300 \mathrm{~m} / \mathrm{sec})$ motions. It is clear that the response under asynchronous motion are excited by additional higher modes different than that one under synchronous motion, thus the response is amplified largely. 


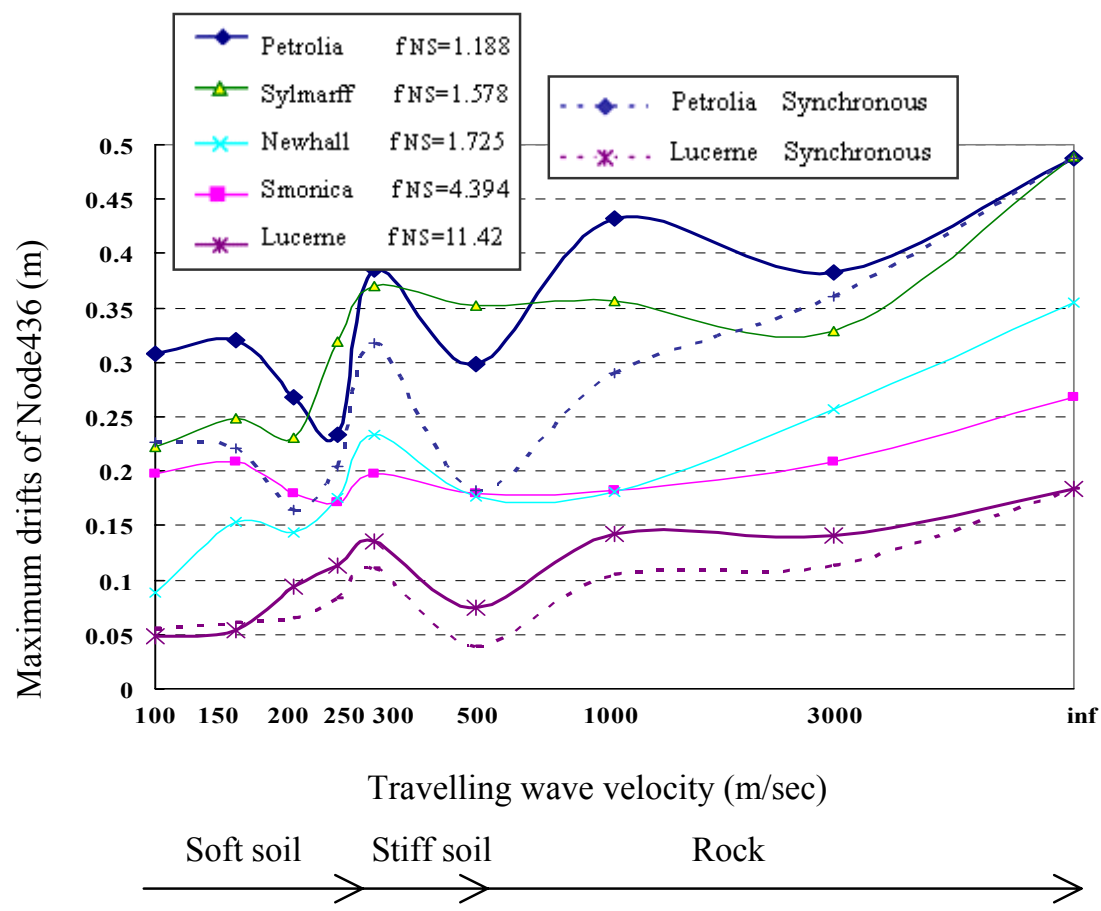

Figure 8: The variation of drifts with the travelling wave velocities at Node436.

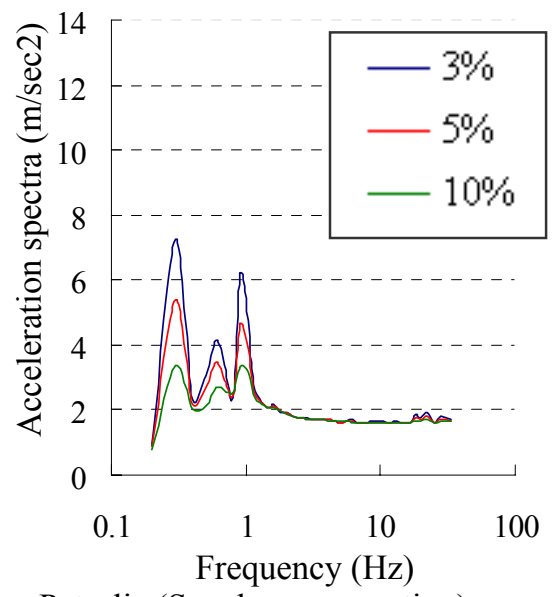

Petrolia (Synchronous motion)

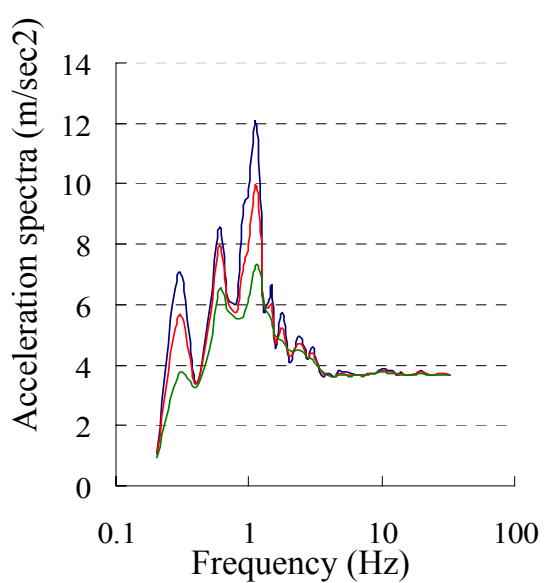

Petrolia (Asynchronous motion) $\mathrm{Vs}=300 \mathrm{~m} / \mathrm{sec}$

Figure 9: Response spectra of acceleration at Node436 under synchronous and asynchronous motions. 


\section{Conclusions}

It can be concluded from the previous study that:

$\diamond$ The bridge response under low frequency earthquakes was much higher than its response to earthquakes of higher frequencies of similar energy, this is due to the resonance caused when earthquake frequency match some dominant frequencies of the bridge vibrating modes.

$\diamond$ The wave propagation along the bridge deck has a significant impact on the structure response since it may excite higher modes of the structure which were not excited under synchronous motion. The effect of travelling wave velocities lower than $1000 \mathrm{~m} / \mathrm{sec}$ on long span bridges should be investigated carefully according to the soil properties between supports

$\checkmark$ The combination of two aspects: the low dominant frequency component which characterize the earthquake motions, and the pseudo static component which arise in the asynchronous motions, will increase the response largely and more studies are required in this field.

\section{References}

[1] Wang, J., Hu. S. \& Wei. X., Effects of engineering geological condition on response of suspension bridges, Soil Dynamics and Earthquake Engineering, Vol. 18, pp.297-304, 1999.

[2] Bogdanoff, J. L., Goldbeg, J.E. \& Schiff, A.J., The effect of ground transmission time on the response of long structures, Bulletin of the Seismological Society of America, Vol. 55 (No.3), pp. 627-640, 1965.

[3] Vanmarcke, E.H., Structural response to earthquakes, Seismic risk and Engineering Decision, C. Lomnitz, (ed), McGraw-Hill: New York, N.Y, 1977.

[4] Werner, S.D., et al., Structural response to travelling seismic waves, Journal of the Structural Division, ASCE, Vol. 105, No.ST12, pp.25472564, 1979.

[5] Somaini, D.R., Seismic behaviour of girder bridges for horizontally propagating waves, Earthquake engineering and Structural Dynamics, Vol.15, pp.777-793, 1987.

[6] Bayrak, O., Effect of multiple seismic input on the response of long multispan bridges, Eleventh world conference on earthquake engineering, 1996.

[7] Monti, G., Nuti, C. \& Pinto, P.E., Nonlinear response of bridges under multi support excitation, Journal of Structural Engineering, ASCE, Vol.122 (No.10), 1996.

[8] Tzanetos, N., Elnashai, A.S., Hamdan, F. \& Antoniou, S., Inelastic dynamic response of RC bridges to non-synchronous earthquakes input motion, ESEE Research Report No.98-6, Civil engineering department, Imperial college, London, UK, 1988.

[9] Wang, A., Carr, N., Cooke. \& Moss, P., Wave passage effect on the seismic response of long bridges, 2003 Pacific conference on earthquake engineering, 2003. 
[10] Burdette, N.J., Elnashai, A.S., Lupoi, A. \& Sextos, A.G., Effect of synchronous earthquake motion on complex bridges, I: Methodology and input motion. ASCE, pp. 158-165, 2008.

[11] Watanabe, G., Iiyama, K. \& Kawano, N. 2007 Niigata Chuetsu-oki earthquake Field reconnaissance Report, 2007.

[12] Furumura, T., Computer simulation of Long-period ground motions from 23October2004 Mw6.6 Niigata-ken Chuetsu Earthquake Japan (Chapter2), Solid Earth Simulation, pp.119-122, 2005.

[13] Koketsu, K., Hatayama, K., Furamura, T., Ikegami, Y. \& Akiyama, S., Damaging long-period ground motions from the 2003 Mw8.3 Tokachi-oki Japan earthquake, Seismological research letters, Volume76, pp.58-64, 2005.

[14] Clough, R.W. \& Penzien, J., Dynamic of structures, McGraw-Hill: New York, 1993.

[15] Ide, S. \& Shelly, D.R., Mechanism of deep low frequency earthquakes: Further evidence that deep-non volcanic tremor is generated by shear slip on the plate interface, AGU, 2007.

[16] Jousset, P. \& Douglas, J., Long period earthquake ground displacements recorded in Guadeloupe Frensh Antilles, Earthquake Engineering and Structural Dynamics, pp.949-964, 2007.

[17] Hays, W.W., Facing geologic and hydrologic hazards- earth science considerations: U.S. Geological survey professional paper1240B, 1981.

[18] Hwang, H., Lin, C.K., Yeh, Y.T., Cheng, S.N. \& Chen, K.C., Attenuation relations of Arias intensity based on the Chi-Chi Taiwan earthquake data, Soil Dynamics and Earthquake Engineering, pp.500-512, 2004. 